\title{
What representations am I using in my courses? Here's an "app" for that!
}

\section{Elif Miskioglu, Bucknell University}

Elif Miskioglu is currently an Assistant Professor of Chemical Engineering at Bucknell University. She graduated from Ohio State University in 2015 with a PhD in Chemical Engineering, and is interested in student learning in engineering. 


\title{
Title: What representations am I using in my courses? Here's an "app" for that!
}

\begin{abstract}
$\underline{\text { Abstract }}$
As engineering educators, we are equipping technical experts with the skills to succeed in their profession, as well as make significant contributions to society. Problem solving and critical thinking skills are the foundation of engineering. These require not only technical (content) skills, but also fluency in engaging with a variety of information. Consequently, students who are comfortable with engaging multiple representations of information are likely also more robust problem solvers and critical thinkers.
\end{abstract}

We are engaged in a multi-phase investigation to study whether exposure to diverse representations results in statistically significant differences in student problem solving, critical thinking, or communication skills. To accomplish this, it is useful for educators to be able to identify and track the representations used in their individual classes, as well as throughout degree programs. The current work was conceived following a study conducted in the chemical engineering department at a large Midwestern university. Observations from this study demonstrated that different instructors for the same course exhibited similar tendencies on exam problem representations. Furthermore, students were less successful on concept inventory problems using representations that were under-utilized by their instructors. Instructors involved in the study were also interested in further utilizing the "representations rubric" developed for this study, and curious as to whether these representation biases persisted through other courses in their degree program. To this end, we are developing an "app" that allows instructors to track the diversity of course experiences they are exposing students to by recording the "experience type" (e.g., lecture, homework problem, exam question) and the representation used (e.g., active, intuitive, visual). The "app" will record this information, and present longitudinal summaries of representations favored by the instructor, highlighting which representations students may not be exposed to frequently.

When used across a course or a degree program, this technology can serve as both a formative and summative assessment of instructional strategies. In this work-in-progress paper, we will describe the "app", its features, and plans for beta-version testing. We will also highlight how this "app" will be used to study prevalent representations in chemical engineering across institutions, and whether diversifying course experiences leads to greater problem solving capabilities in students.

\section{Purpose and Scope of Paper}

The described "app" is part of a long-term project to study the effects of exposure to diverse representations on chemical engineering student problem solving, critical thinking, and communication skills. The "app" is being developed primarily as a data-collection tool, but we also foresee potential implications for classroom use (depending on study results) as later described. At the time of this work-in-progress publication the "app" is in initial stages of development. Thus, we outline the framework for the "app" idea in detail, and describe some "app" features prior to broad dissemination of the "app" for beta-testing next year. 


\section{$\underline{\text { Introduction and Motivation }}$}

Engineering is often equated with problem solving. Critical thinking and communication ${ }^{1}$ are also essential skills for the professional engineer. ${ }^{2}$ The ability to think about problems critically is essential to being able to solve them, and the ability to communicate is also essential. Communication is important not only to share solutions, but also for understanding the problem and gathering the necessary information to solve it. If diversifying course experiences is shown to increase student problem-solving, critical thinking, and communication skills, we must focus our attention on how this diversity can be achieved in a manner that is low cost with respect to both time and money for the instructor. We believe that the "app" described may result in a viable new instructional and curricular planning tool for use in engineering education.

As mentioned, the work described here is Phase I of a long-term project to study the effects of exposure to diverse representations on chemical engineering student problem solving, critical thinking, and communication skills. Rigorous curricular and disciplinary biases may limit students' natural exposure to different representations in the ordinary course of their degree program. This may be hindering our students in their ability to tackle the increasingly difficult challenges of modern society. Our best attempts to re-create "real-world" experiences in our classrooms are still moderately controlled proxies, and in the "real world," students will encounter problems, data, and information presented in all sorts of ways. It is our responsibility as educators to prepare them for these encounters.

While multiple representations are promoted for their ability to engage different types of learners and diversify teaching styles, there is little research available on their effect on problem solving and critical thinking skills. Furthermore, the work that is available often focuses on a single representation (e.g., visualization ${ }^{3}$ ). Because exposure to diverse representations will theoretically allow students to be more versatile thinkers, we believe this will result in greater development of problem solving and critical thinking skills. To be able to study this, we must first develop a framework to categorize representations, and assess what the "standard" representations for a given curriculum or course are. Having originated in the discipline of chemical engineering, this work will initially focus on that discipline before expanding to others. Over the course of this project, we will:

1) Develop a framework for categorizing representations (Phase I)

2) Adopt this framework into a user-friendly web-based electronic tool (the "app") that will allow instructors to categorize the representations used in their course, track these representations over time, and see summaries of their representation biases (Phase II)

3) Test the "app" for usability, validity, and reliability (Phase II)

4) Use the "app" to study representations used in chemical engineering courses at institutions of interest (Phase III)

5) Report on institutional or course trends seen in Phase III, and identify "standard" representation experience (Phase III)

6) Use data from Phase III to select courses of interest for comparative study. Use pre- and post-semester problem solving and critical thinking analyses to compare a "standard" section of course with one which has been redesigned to expose students to a balanced variety of representations (Phase IV) 
Focus of the current work-in-progress publication will be on Phase I (complete, reported elsewhere $^{4}$ ) and Phase II (in progress) with some description of the vision for upcoming Phases III and IV.

\section{Background}

Human bias is well documented throughout history, and thus it is not surprising that instructors may have distinct biases in the representations used in their classes. These biases may stem from personal experience, disciplinary conventions, ${ }^{5}$ institutional conventions, or historical practice. Evidence from a study of representations used on exam problems in a sophomore-level chemical engineering class at a large public research institution showed little variation in preferred representations among the five different instructors and supports the influence of strong disciplinary biases. ${ }^{4,6}$

This work has sparked further interest in exploring the potential homogeneity of experiences chemical (and other) engineering students are exposed to. Additionally, the instructors in the original study were highly interested in using the framework for categorizing problem representations in their own pedagogy. ${ }^{6}$ Since then, a more robust framework has been developed that considers both STEM and non-STEM disciplines, and efforts are being pursued to develop a user-friendly "app" that allows instructors to easily access and utilize this framework., ${ }^{4,6}$

Phase I: Framework for Categorizing Representations and Introduction to Associated Rubric In Phase I we developed a framework for categorizing representations ${ }^{4,6}$ based on the FelderSilverman model of learning styles. ${ }^{7,8}$ While learning styles themselves are a highly controversial topic in higher education, ${ }^{9-12}$ we propose reconsidering what learning styles represent. Viewed through a slightly different lens, Felder and Silverman's model of learning and teaching styles provide a basic language and categorization for the various ways in which individuals engage with information. ${ }^{6}$ In the original model, the dimensions of learning are described as how one might "process, perceive, receive, and understand" new material while learning. The dimensions of teaching describe "student participation, type of content, presentation, and perspective." Applying this model more broadly, the dimensions of learning and teaching styles can be seen to describe not only forms of engagement when learning or teaching new material, but also generalized forms of engagement with information. In the context of categorizing course experiences, we reconsider learning styles to describe forms of engagement with problem solutions, and teaching styles to describe forms of engagement with problem presentation as shown in Figure 1. 




Figure 1. Felder-Silverman model of learning (top) and teaching (bottom) styles reconsidered for categorization of representations (problem solution and presentation). ${ }^{8}$

Using this perspective on the Felder-Silverman model, we have previously developed a rubric guide instructor's in categorizing problem presentation and solution. ${ }^{4,6}$ The original rubric was developed for use in a chemical engineering curriculum, however, it has the potential to be more broadly applied throughout STEM disciplines. ${ }^{4,6}$

\section{Phase II: “App” Development and Vision for Research and Classroom Use}

“App” Development: While the rubric developed in Phase I is valuable for categorizing representations used in classrooms, it is not sufficiently user-friendly for broad dissemination and large study data collection. Thus, we are in the development stages of a user-friendly online platform "app" that will not only allow instructors to apply the rubric but also provide instructors with the ability to track and summarize trends across a period of time or repeated iterations of a full course. Furthermore, this "app" will allow us to easily compile a database of representation use for Phases III and IV.

Vision for Use: The final "app" is envisioned to function much like the increasingly common workout or diet tracking apps. Instructors will be able to access the rubric and assign categorizations to the different types of activities they use (e.g., lecture, laboratory, exam, homework, etc.). An important "app" feature will be tracking both use and frequency of use. For example, in a given class period an instructor may have the students engage in 3 active, 2 reflective, 1 verbal, and 1 intuitive representation. The "app" will allow the instructor to record the class activity, the representations used, and the frequency of each representation. The "app" will provide the ability to summarize trends through aggregate graphs of representations used by the class activity, specific class, semester, and et cetera. Beta version testing will elucidate missing functionality and programming bugs, after which the app will be studied for validity and reliability.

Phases III and IV: Study on Intentional Use of Multiple Representations in the Classroom

Ultimately, this "app" will serve as a data collection tool for identifying commonly used categorizations in chemical engineering courses by specific course and institution type. This will allow us to identify what a "standard" set of representations might look like for a specific course 
(Phase III), to be used in our subsequent study of a "standard" course evaluated against one engineered to have diverse representations (Phase IV).

To gather the data necessary for Phase III, the app will be disseminated to study-site institutions' chemical engineering faculty. We will be looking at specific courses in the core curriculum, such as mass and energy balances or thermodynamics, to understand the "standard" representations used in each. Courses at differing types of institutions (e.g., large public research institutions vs. small, private liberal arts institutions) with chemical engineering programs will be compared.

In Phase IV, we will use our knowledge of a "standard" representations experience in the aforementioned core courses to run a study comparing a course section with "standard" representations against a section designed to have diverse representations. Specifically, we will evaluate gains in problem solving, critical thinking, and communication skills in each of the sections.

\section{$\underline{\text { Summary and Broader Impact }}$}

The framework and "app" described here are a data collection tool for a future large scale study. To be able to study whether diverse representations do affect students' problem solving, critical thinking, and communication skills, we first need to define our categorizations of representations and develop a tool that will enable us to gather data at the scale needed.

If diverse representations do in fact positively influence students' problem solving, critical thinking, and communication skills, the "app" may become a useful instructional or curricular planning tool. Faculty who have been exposed to the rubric form of the categorization framework have already shown interest in applying this framework of categorizations to their course planning. While the current application is limited to chemical engineering, we foresee that the framework could be easily adapted to any STEM discipline, and additionally modified for non-STEM disciplines. Furthermore, a student version could be developed that allows students to track the representations they encounter through their coursework and extracurricular activities, empowering students to take greater ownership of their education.

\section{$\underline{\text { References }}$}

1 ABET. Criteria For Accrediting Engineering Programs. (2014).

2 Phase, I. Educating the Engineer of 2020:: Adapting Engineering Education to the New Century. (National Academies Press, 2005).

3 Ainsworth, S. in Visualization: Theory and practice in science education 191-208 (Springer, 2008).

4 Miskioğlu, E. E. in Frontiers in Education Conference (FIE), 2016 IEEE. 1-7 (IEEE).

5 Kolb, D. A. Learning styles and disciplinary differences. The modern American college, 232-255 (1981).

6 Miskioğlu, E. E. Learning in Style: Investigation of Factors Impacting Student Success in Chemical Engineering at Individual and Team-Levels with a Focus on Student Learning Styles, The Ohio State University, (2015).

$7 \quad$ Felder, R. M. \& Spurlin, J. Applications, Reliability and Validity of the Index of Learning Styles. Int. J. Engng Ed 21, 103-112 (2005).

8 Felder, R. M. \& Silverman, L. K. Learning and Teaching Styles in Engineering Education. Engr Education 78, 674-681 (1988). 
9 Coffield, F., Moseley, D., Hall, E. \& Ecclestone, K. Learning styles and pedagogy in post-16 learning: A systematic and critical review. (2004).

10 Coffield, F., Moseley, D., Hall, E. \& Ecclestone, K. Should we be using learning styles?: What research has to say to practice. (2004).

11 Pashler, H., McDaniel, M., Rohrer, D. \& Bjork, R. Learning Styles: Concepts and Evidence. Psychological Science in the Public Interest 9, 105-119, doi:10.1111/j.15396053.2009.01038.x (2008).

12 Rohrer, D. \& Pashler, H. Learning styles: where's the evidence? Medical Education 46, 634-635, doi:10.1111/j.1365-2923.2012.04273.x (2012). 